\title{
The loop antenna with director arrays of loops and rods
}

\section{Appel-Hansen, Jørgen}

\section{Published in:}

I E E E Transactions on Antennas and Propagation

Publication date:

1972

\section{Document Version}

Publisher's PDF, also known as Version of record

Link back to DTU Orbit

Citation (APA):

Appel-Hansen, J. (1972). The loop antenna with director arrays of loops and rods. I E E E Transactions on Antennas and Propagation, 20(4), 516-517.

\section{General rights}

Copyright and moral rights for the publications made accessible in the public portal are retained by the authors and/or other copyright owners and it is a condition of accessing publications that users recognise and abide by the legal requirements associated with these rights.

- Users may download and print one copy of any publication from the public portal for the purpose of private study or research.

- You may not further distribute the material or use it for any profit-making activity or commercial gain

- You may freely distribute the URL identifying the publication in the public portal

If you believe that this document breaches copyright please contact us providing details, and we will remove access to the work immediately and investigate your claim. 
and mounting the 26- and 104-element arrays. Low-loss flexible coaxial feed line used in the 104-element array was kindly provided by W. K. Klemperer from NOAA's Space Environment Laboratory, Boulder, Colo. K. Neal, also of the Space Environment Laboratory, provided the time-shared computer program used for impedance transformation.

\section{REFERENCES}

[1] J. D. Kraus, Antennas. New York: McGraw-Hill, 1950, cf. ch. 4. 2] P. V. Handel and W. Pfister, "Ausbreitung der Mikrostrahlen," Zentrale für technischwissenschaftliches Berichtswesen iber Luftfahrtforschung, Germany, Res. Rep. FB338, May 6, 1935 .

[3] S. I. F. Fayard, Au brevet d'invention No. 782.801 (1ns addition). Perfectionnements aux antennas de T.S.F., Ministry of Commerce and Industry, France, patent published Sept. 12, 1935.

[4] H. B. Hollman, Physik und Technik der Ultrakurzen Wellen. Berlin, Germany: Springer,, 1936. (See "Konzentrische Rohrleitung als Obserwellenantenna,", after Pfister in Fig. 84. pp. 74 of vol. II, "Die ultrakurzen Wellen in der Technik."

[o] H. A. Wheeler, "A vertical antenna made of transposed sections of coaxial cable," in 1956 IRE Conv. Rec., vol. 4 , pt. 1 .

[6] G. R. Ochs," "The large $50 \mathrm{Mc} / \mathrm{s}$ dipole array at Jicamarca Radar observatory," Nat. Bur. Stand, Boulder, Colo., Rep. 8772, Mar. 5 , 1965 .

\section{The Loop Antenna with Director Arrays of Loops and Rods}

\section{J. APPELHANSEX}

Abstract-Experiments indicate that the gain of a Yagi-Uda antenna arrangement depends only upon the phase velocity of the surface wave traveling along the director array and not to any significant extent upon the particular forms of the director elements.

In the common Yagi-Uda antenna, rod directors are usually used. According to Ehrenspeck and Poehler [1], the phase velocity of the surface wave traveling along the array of rod directors can be used as the design criterion for maximum gain. This seems to indicate that the magnitude of the gain depends only on the phase velocity of the surface wave and not on the particular form of the director elements. The purpose of the present investigation is to verify whether an array of short-circuited loops in front of the loop antenna provides the same gain as an array of rod directors.

In Fig. 1, the geometry of the directive loop array antenna is shown. It consists of a feeding loop, a reflector loop, and an array of equispaced loop directors of equal diameter. The feeding loop is a shielded loop made of coaxial cable of $4-\mathrm{mm}$ diameter. The reflector and director loops are made of $1.25-\mathrm{mm}$ aluminum plate. The difference between inner and onter radius of these flat-plate loops is $1 \mathrm{~cm}$. When a radius of a loop is indicated, it designates the average radius of the loop in question. The measurements were carried out in a radio anechoic chamber at $650 \mathrm{MHz}$. The gain over an isotropic radiator was measured.

The measurements started with an optimization of the diameter of the shielded feeding loop. A gain of $3.4 \mathrm{~dB}$ was obtained at a circumference of $k a_{f}=1.10$, where $k=2 \pi / \lambda$ is the wavenumber, $\lambda$ is the wavelength, and $a_{f}$ the radius of the feeding loop.

After this optimization, a reflector of the same diameter as the feeding loop was added. By optimizing several times in turns, the spacing between feeding loop and reflector loop, the diameter of the reflector, and the diameter of the feeding loop, an optimum gain of $7.8 \mathrm{~dB}$ was obtained. This compares well with results obtained by Ito et al. [2].

In front of the feeding arrangement so obtained, a director array of short circuited loops with an equidistance of $0.2 \lambda$ was placed. The length of this array was varied in steps of $0.4 \lambda$ from $0 \lambda$ to $4 \lambda$. For each length, the gain was measured as a function of the radius

Manuscript received February 3, 1972

Laboratory of Flectromagnetic Theory, The Technical University, Lyngby, Denmark.

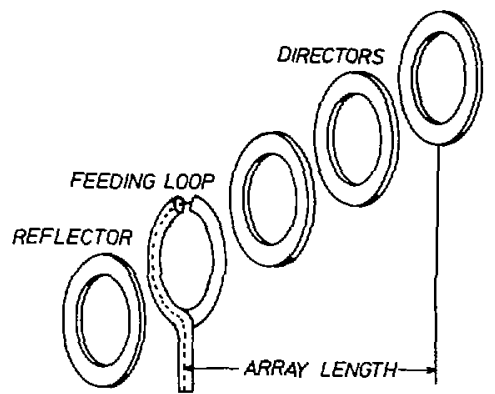

Fig. 1. Directive loop array antenna.

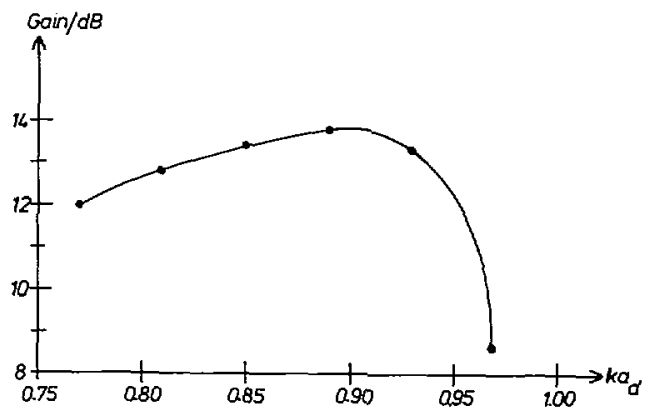

Fig. 2. Gain as function of $k a_{d}$. Array length $2 \lambda$.

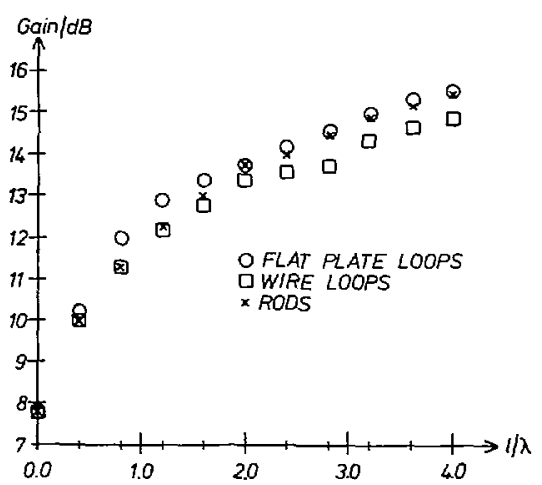

Fig. 3. Gain as function of array length.

$a_{1}$ of the director loops. In Fig. 2, as an example, the gain as a function of $k a_{d}$ for an array $2 \lambda$ long is shown. It is seen that a maximum gain of $13.8 \mathrm{~dB}$ was measured. In Fig. 3 , the maximum gain obtained in this manner by varying the director loop diameter for the different array lengths $l$ is shown. The same measurement procedure was carried out for a director array consisting of $2 \mathrm{~mm}$ wire loops. In completion it should be mentioned that the results do not change when the loop directors are open circuited in one or both of their current minima.

Following this, an array of rod directors with equispacing $0.2 \lambda$ was placed in front of the feeding arrangement. This time, by varying the length of the rod directors, the maximum gain for several array lengths between $0.4 \lambda$ and $4.0 \lambda$ was measured. For comparison between the three types of director elements, the results for the rod directors are also shown in Fig. 3.

From Fig. 3, we may conclude that there is no more than about 1- $\mathrm{dB}$ difference between the gain of the various types of director elements. For the array lengths considered the flat-plate loops seem to be more effective for lengths less than $2 \lambda$, whereas the wire loops are the least effective for lengths larger than $2 \lambda$. Due to the small difference between the results, the experiments seem to confirm that the maximum gain only depends upon the phase velocity of the surface wave and not upon the particular form of the director elements. 
In all the experiments, the same feeding arrangement has been used and the cross section of the loops and rods has not been optimized. Furthermore, for each type of director elements only equispaced elements of the same magnitude has been considered. When these constraints are alleviated, a higher gain can be obtained.

A reflection type of arrangement, where the surface wave is reflected from the end, is known to give a gain increase [3]. However, it is not expected that any particular type of director elements will be significantly more effective than any other types.

\section{ReFERENCES}

[1] H. W. Ehrenspeck and H. Poehler, "A new method for obtaining maximum gain from Yagi antennas." IRE Trans. Antennas Propagat., moi. AP-7. pD. 379-386, Oct. 1959 .

[2] S. Ito. N. pp. 3aki, and T." Sekigucht, "An investigation of the array of circular-loog antennas," IEEE Trans. Antennas Propagat., vol. AP-19, pp. 469-485, July, 1971

[3] J. H. Bojsen, H. Schjaer-Jacobsen, E. Nilsson, and J. Bach Andersen, "Maximum gain of Yagi-Uda arrays," Electron. Ĺtet., vol. 7, no. 18, pp. 531-532, Sept. 1971 .

\section{Comments on "Diffraction by Arbitrary Cross-Sectional Semi-Infinite Conductor"}

\section{NAGAYOSHI MORITA}

Abstract-The far scattered fields by a semi-infinite conductor are composed of the geometric-optics and the diffraction field. By applying the technique of complex number integral, the separation of these two fields in the neighborhood and other region of the geometrical shadow and reflection boundaries is clarified. This was ambiguous in the above paper. 1

When the incident electric field

$$
E_{z}^{\text {inc }}=E_{0} \exp \left(-j X \cos \theta-j\left(Y+Y_{0}\right) \sin \theta\right\}
$$

is scattered by a semi-infinite conductor shown in Fig. 1, the total scattered field can simply be expressed as

$$
\begin{gathered}
E_{z^{\text {east }}}(X, Y)=-\frac{1}{4}\left(\frac{\mu}{\epsilon}\right)^{1 / 2}\left[\int_{0}^{\infty} H_{0}^{(2)}\left(\left[\left(X-X_{1}^{\prime}\right)^{2}+\left(Y+Y_{0}\right)^{2}\right]^{1 / 2}\right)\right. \\
\left.\cdot K_{u 1}\left(X_{1}^{\prime}\right) d X_{1}{ }^{\prime}+\int_{\Delta} H_{0}^{(2)}\left(\left|R-R^{\prime}\right|\right) \cdot K_{e}\left(R^{\prime}\right) d c^{\prime}\right]
\end{gathered}
$$

which corresponds to (18) in the above paper. ${ }^{1}$ Where, the symbol $\Delta$ means the line region where $K_{e}$ is assumed not to be zero, and where

$$
K_{u 1}(X)=2\left(\frac{\epsilon}{\mu}\right)^{1 / 2} \sin \theta \cdot E_{0} \exp (-j X \cos \theta) .
$$

Only the second term of (2) was discussed in the above paper. ${ }^{1}$

In this communication, the first term

$$
\begin{aligned}
\mathrm{I}= & -\frac{1}{4}\left(\frac{\mu}{\epsilon}\right)^{1 / 2} \int_{0}^{\infty} H_{0}^{(2)}\left(\left[\left(X-X_{1}^{\prime}\right)^{2}+\left(Y+Y_{0}\right)^{2}\right]^{1 / 2}\right) \\
& \cdot K_{u_{1}}\left(X_{1}^{\prime}\right) d X_{1}^{\prime} \\
= & -\frac{1}{2} \cdot E_{0} \sin \theta \cdot \int_{0}^{\infty} H_{0}^{(2)}\left(\left[\left(X^{\prime}-X\right)^{2}+\left(Y+Y_{0}\right)^{2}\right]^{1 / 2}\right) \\
& \cdot \exp \left(-j X^{\prime} \cos \theta\right) d X^{\prime}
\end{aligned}
$$

Manuscript received October 5, 1971 ; revised February 14, 1972.

The author received October 5, 1971; revised Fobrar Englneering, Faculty of Engineering, Osaka University, Suita, Osaka, Japan 565 .

358-365, May 1971 .

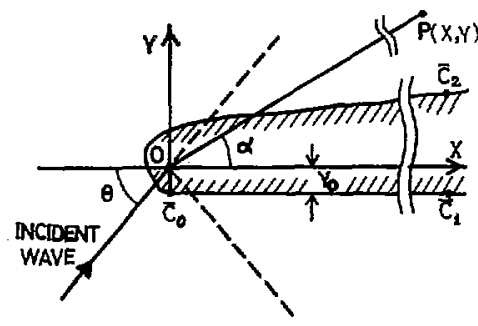

Fig. 1. Semi-inflnite conductor.

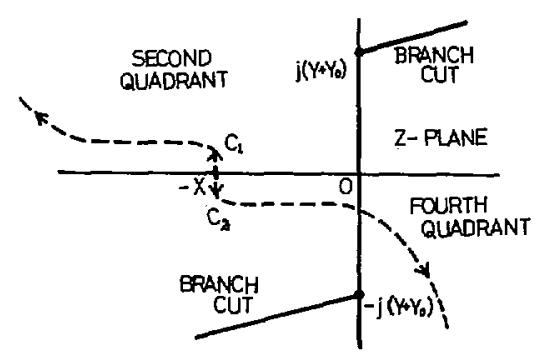

Fig. 2. Complex $z$ plane.

is investigated in detail for the case where $X$ and $Y$ tend to infinity. The integral with complex number $z$ :

$$
\mathrm{II}=\int H_{0}^{(2)}\left(\left[z^{2}+\left(Y+Y_{0}\right)^{2}\right]^{1 / 2}\right) \exp (-j z \cos \theta) d z
$$

is used for calculation of (4).

Since

$$
H_{0}^{(2)}\left(\left[z^{2}+\left(Y+Y_{0}\right)^{2}\right]^{1 / 2}\right) \rightarrow O\left(e^{-|s|}\right)
$$

in the regions $\pi / 2<\arg (z)<\pi$ (the second quadrant) and $(3 / 2) \pi<\arg (z)<2 \pi$ (the fourth quadrant), where $z=\sigma+j \zeta$, it is convenient to set the branch cuts and the integral contours $C_{1}$ and $C_{2}$ as shown in Fig. 2. Both contours $C_{1}$ and $C_{2}$ start from the point $(-X, 0)$ and are vertical straight lines in the neighborhood of $(-X, 0)$. The contours $C_{1}$ and $C_{2}$ are entirely to the left and right of $(-X, 0)$, and above and below the real axis; they terminate at infinity in the second and fourth quadrants, respectively.

Next, it will be shown that only the neighborhood of the point $(-X, 0)$ contributes to the integration of II on the contours $C_{1}$ and $C_{2}$. Assume that

$$
X \text { and } Y \rightarrow \infty \text { and } X, Y \gg|\zeta|
$$

where $|\zeta|$ means the absolute value of $\zeta$. The point $z$ on $C_{1}$ and $C_{2}$ can be written as

$$
z=-X+\sigma+j \zeta
$$

then,

$$
\begin{aligned}
{\left[z^{2}+\left(Y+Y_{0}\right)^{2}\right]^{1 / 2}=} & \left(\left[(X-\sigma)^{2}+\left\{\zeta+\left(Y+Y_{0}\right)\right\}^{2}\right]\right. \\
& \left.\cdot\left[(X-\sigma)^{2}+\left\{\zeta-\left(Y+Y_{0}\right)\right\}^{2}\right]\right)^{1 / 4} \\
& \cdot \exp \left\{-j \frac{1}{2}\left(\tan ^{-1} \frac{\zeta+\left(Y+Y_{0}\right)}{X-\sigma}\right.\right. \\
& \left.\left.+\tan ^{-1} \frac{\zeta-\left(Y+Y_{0}\right)}{X-\sigma}\right)\right\} .
\end{aligned}
$$

Using (7) and (9),

$$
\operatorname{Im}\left(\left[z^{2}+\left(Y+Y_{0}\right)^{2}\right]^{1 / 2}\right) \cong-\frac{\zeta(X-\sigma)}{\left[(X-\sigma)^{2}+\left(Y+Y_{0}\right)^{2}\right]^{1 / 2}} .
$$

When $z$ is on either $C_{1}$ or $C_{2}$,

$$
\begin{aligned}
-\frac{\zeta(X-\sigma)}{\left[(X-\sigma)^{2}+\left(Y+Y_{0}\right)^{2}\right]^{1 / 2}} & \leq-\frac{\zeta X}{\left[X^{2}+\left(Y+Y_{0}\right)^{2}\right]^{1 / 2}} \\
& \cong-\zeta \cos \alpha
\end{aligned}
$$

